\title{
BIOREMEDIATION: THE ECO-FRIENDLY SOLUTION TO THE HAZARDOUS PROBLEM OF ENVIRONMENTAL POLLUTION
}

\author{
Susmita MUKHERJEE ${ }^{1}$, Rajiv NARULA ${ }^{2}$, Shreya BHATTACHARJEE ${ }^{1}$, \\ Debankita DUTTA ${ }^{1}$, Indrani BOSE ${ }^{1}$, Jitesh MAHAKUD ${ }^{1}$, Sharanya PAUL ${ }^{1}$, \\ Sourish BHATTACHARJEE ${ }^{1}$, Sonali PAUL ${ }^{1 *}$ \\ ${ }^{1}$ Department of Biotechnology, University of Engineering and Management, University Area, \\ Plot No. III - B/5, New Town, Action Area - III, Kolkata, 700160 West Bengal, India \\ ${ }^{2}$ Department of Chemistry \& Environmental Science, State University of New York (SUNY) at Canton, \\ Cook Hall 208, 34 Cornell Drive, Canton, NY 13617, (315) 386-7414, USA
}

Received 30 October 2020; accepted 31 December 2020

\begin{abstract}
Highlights
The quality of the environment is deteriorating due to the accumulation of pollutants.

Traditional physical and chemical methods for environmental pollutant cleanup has several limitations.

$>$ Bioremediation is an emerging concept to restore the quality of the environment.

> Microbes, plants, algae are important components which convert hazardous substances into its less toxic forms.

This paper analyzes the methodologies along with the benefits and limitations of adopting the bioremediation technique as a promising environmental management technology for the future.
\end{abstract}

\begin{abstract}
Bioremediation is a technique to enhance natural biological processes to rectify polluted groundwater, soil, and even entire habitats. Bioremediation techniques use biological agents to act upon hazardous, toxic materials and subsequently convert them into less toxic substances.

Microbes are organisms ubiquitously present in the biosphere. These microorganisms are the main agents that remediate toxic and polluted environmental conditions. Highly polluted areas can be rectified using proper bioremediation procedures and interventions. In this review we have studied the different bioremediation techniques which can be utilized to correct the harmful effects of environmental pollution. In this study we have also emphasized on the benefits of adopting bioremediation as an efficient alternative technique in comparison to the traditional physical and chemical methods to restore the healthy environmental conditions.
\end{abstract}

Keywords: environmental pollution, environmental sustainability, bioremediation, microorganisms, environment monitoring.

\section{Introduction}

\section{Environmental pollution - the problem}

Pollution is the harmful environmental alteration, entirely or partially due to anthropogenic activities, through changes in the chemical and physical constitution of the material environment, and its negative effect on living beings.

Environmental pollution has long term deleterious effects on developed and developing countries alike. The decline in environmental quality of the different ecosystems expresses itself by reduction in vegetation cover, reduction in the spectrum of biological diversity, habitat loss, and the presence of accumulated toxic chemicals in the entire biosphere along with its components. Pollution can have many causal factors but is generally believed due to rapid urbanization and industrialization, and non-judicious use of non-renewable resources, ever-increasing accumulation of industrial wastes, toxic effluents which results in deteriorating environmental quality.

In studies conducted worldwide, innumerable point and non-point sources of pollution were proved to be

${ }^{*}$ Corresponding author. E-mail: sonaliuem@gmail.com 
the causal factors identified to change the condition of the atmosphere, hydrosphere, and lithosphere. A pollutant is the substance that causes pollution by toxic chemical, geochemical substances, biological agents or physical substances like different varieties of harmful radiations, that when build up in the environment, results in adverse effects. Such undesirable effects may also be evidenced by its effect on the natural resources or climate change (Rai \& Chutia, 2016).

\section{Methodology}

This review paper comprises of literature search from various websites including www.pubmed.gov, scholar.google. com, Web of Science, Scopus. Literature study was carried out using the principal search terms of environment, pollution, microbes, bioremediation. The inclusion criteria were to incorporate relevant current literature which were primarily published after the year 2000 and provided valuable insight into the review topic. These comprised the followed review protocol.

\section{Bioremediation - guiding principles}

Bioremediation is the technique by which hazardous wastes are degraded by microorganisms to a comparatively harmless state, or to bring down the concentration of the contaminants well within permissible levels. Bioremediation employs suitable living organisms like bacteria, fungi, or plants, which have the inherent abilities to transform the contaminants to its detoxified state. The bioremediation technique requires the presence of the required biological agents in the required site under the optimum environmental conditions for the highest rate of biodegradation.

The overall concept and development of bioremediation technology is developed keeping in mind the necessity for the removal of various hazardous pollutants from all components of the biosphere. It can remediate polluted ground water, polluted atmosphere, biomass, or other components of the environment. Bioremediation is effective against a wide spectrum of pollutants. Apart from cleaning up the ground and surface waters, microorganisms find application for the treatment of chemical pesticides present in the runoff water from the agricultural fields, industrial effluents, components of crude oil present in oil spill, and compounds such as chlorine containing solvents, chlorofluorocarbons, and other synthetic organic compounds (Zouboulis \& Moussas, 2011).

\subsection{Necessity of adopting bioremediation: the ultimate solution}

Environmental pollution is the chronic build up of hazardous heavy metals in the different dimensions of the biosphere that deteriorates the efficiency of the environment to sustain life. The global population boom which leads to increase in harmful anthropogenic activity through non scientific use of natural resources, generation and non systematic waste disposal has resulted in deterioration of environmental quality. In addition, the rapid scientific and technological advancements, industrialization, and urbanization have increased generation of wastes, ranging from domestic sewage to nuclear waste, which poses a severe problem for maintenance of sustainable life forms and societies.

The traditional methods of waste disposal such as land fill, heat incineration, and chemical decomposition of waste lacked simplicity, cost reduction, and practical acceptance (Karigar \& Rao, 2011). Moreover, these methods almost always generate toxic by-products and end products. Bioremediation is an economical, and environmentfriendly methodology that consist of techniques to clean up polluted environments (Pushpanathan et al., 2014). In the recent past, different organisms such as bacteria, fungi, algae, and plants were a part of the designing of technology for the deletion of environmental hazards with high amount of success (Vidali, 2001; Leung, 2004).

The bioremediation by microorganisms centers on the remediation of environmental pollutants by the action of microbial enzymes, breaking down the toxic substances into safe products, thereby leading to the reduction of toxicity of these substances. The application of environmental microbes is guided by $\mathrm{pH}$, temperature, oxygen, soil character, moisture, appropriate level of nutrients, and bioavailability of contaminants making it a preferred methodology for remediation of contaminated sites (Dana \& Bauder, 2011). Advances in microbiological techniques have led to the identification, biochemical assay techniques, molecular characterization of metal-resistant, metal accumulating or transforming microorganisms. Molecular and genetic approaches have given us knowledge about the details of interaction of microbes with heavy metals and concluded that it is highly effective for successful environmental remediation measures (Gadd, 2010).

\subsection{Bioremediation - types}

We can classify bioremediation as: in-situ bioremediation is the treatment of a contaminant at the polluted location, and ex-situ bioremediation is the offsite treatment of contaminated soil or water (Azubuike et al., 2016).

Bioremediation, though may sound simple, is a collection of biological processes. This causes difficulty in precisely predicting the effectiveness of an in-situ system, which hampers desining future planning activities. Traditional chemical treatment methods offer a relatively faster process than in-situ bioremediation.

Presence of microorganisms degrading the toxic contaminant, optimum environmental conditions including nutrient levels are determining factors for the success of in-situ bioremediation. Thus when designing a bioremediation technique, it is important to study the site of contamination with a strong emphasis on assessing the possible limiting factors (Frutos et al., 2012). Polluted environmental samples obtained from the contaminated site should be assayed to understand the group of 
microorganisms capable of biodegrading the contaminant. Assessment of polluted subsurface water at the site of contamination should be done to study the role of the physical factors that regulate biodegradation, such as presence of oxygen, nutrient, temperature, and $\mathrm{pH}$.

Not all of the environmental limiting factors are present in easily accessible forms. For example, pollutants are often present in associated and complex forms, and one component in the pollutant may prevent the action of microorganisms. Similarly, less bioavailability of the pollutant is another factor that can reduce the effectiveness of bioremediation, because to be easily biodegraded, the contaminant must be readily accessible to the microorganisms.

Presence of oxygen for aerobic biodegradation in the saturated zone of the soil is one of the most inportant limiting factors for in-situ bioremediation. Oxygen on getting used up, is replenished via aqueous diffusion. Due to these reasons, presence of oxygen often limits the application in groundwater remediation systems. Several methodologies have been developed which replenish oxygen in the soil. The simplest method is to inject air directly into groundwater by the air sparging method. Other methodologies involve adding chemicals into the subsoil that give off oxygen upon chemical reaction.

Nutrients such as nitrogen and phosphorus when exogenously added increases the remediation processes (Barr et al., 2002).

Many polluted sites contain wastes having high carbon content but having less amount of nitrogen and phosphorus. Solutions containing carbon, nitrogen, phosphorus are usually added to make up for the elemental composition. Majority of the in-situ bioremediation applications of the past utilized aerobic biodegradation which is now being slowly replaced by anaerobic processes which is proving to be advantageous. First, maintenance of aerobic conditions is sometimes difficult in the underground zones of the soil. Secondly, some toxic pollutants are resistant to biodegradation in the presence of oxygen. This has necessitated the proposal for the use of several electron acceptors like nitrate $\left(\mathrm{NO}_{3}{ }^{-1}\right)$, sulfate $\left(\mathrm{SO}_{4}^{-2}\right)$, and iron $\left(\mathrm{Fe}^{+3}\right)$ ions, as well as carbon dioxide, in anaerobic degradation. In some cases, the carbon content of added substances such as molasses are degraded by microorganisms in the presence of oxygen which is used up and leads to setting up of anaerobic conditions. Sequential anaerobic/aerobic biodegradation processes has been applied successfully. This approach has been found to be useful for mixed-waste sites.

Cometabolic biodegradation, is another approach of interest in which one component is utilized as source of energy, while simultaneously biodegradation of other compounds is carried on. This approach is useful for the remediation of chlorinated solvents. This can be illustrated by the example, methanotrophic organisms use the enzyme methane monooxygenase to degrade methane $\left(\mathrm{CH}_{4}\right)$, while also degrading other chlorinated solvents, such as trichloroethane $\left(\mathrm{C}_{2} \mathrm{H}_{3} \mathrm{Cl}_{3}\right)$ (Hazen, 2010).

If specific contaminant degrading organisms are not present at the required site, they can be added exogenously.
This technique is known as bioaugmentation. This methodology has certain limitations. Firstly, the newly introduced microbes are weakly established and thus may face difficulties in their survival. Secondly, microorganisms can be trapped in small pores within the soil which makes them inaccessible at the site of contamination. This problem can be circumvented by adding mixtures of bacteria to promote bioremediation at contaminated sites (Herrero \& Stuckey, 2015).

Bioventing is the association of soil venting technology and bioremediation technique applied in the vadose (shallow) zone. Air flows through the contaminated site with a blower or vacuum system, which enhances the presence of oxygen and the rate of biodegradation. (Brusseau, 2019)

\section{Bioremediation strategies}

Bioremediation is a technique utilizing mainly microbial or phyto enzymes to detoxify environmental pollutants. The concept includes biodegradation, which is the biotransformation or microbial or phyto detoxification of pollutants. Mineralization is a technique which converts an organic pollutant to its inorganic version by a consortium of microorganisms. Co-metabolism is a technology which does not require the exogenous addition of carbon or energy for the microbial growth (Skipper \& Turco, 1995). Bioremediation amplifies the process of the natural microbial biodegradation by the addition of nutrients to the microorganisms (biostimulation, biorestoration) or by supplementing an external microbial culture that speedens up the degradation rate (bioaugmentation) (Mackay \& Fraser, 2000). The aim of biological rectification is to bring down the toxic pollutant level to undetectable, nontoxic levels, or to permissible levels (Pointing, 2001).

\subsection{Bacterial and fungal bioremediation strategies}

There is a growing research focus in studying the environmental regulatory effects on the efficiency for remediation of xenobiotic compounds that persist in the terrestrial ecosystems for a very long time period. Fungi colonize the soil ecosystems by their mycelia and by producing extracellular enzymes such as laccases and ligninases. Lesser work has been done to study the effect of changes in water and temperature relations on the efficiency of bioremedial fungi on xenobiotic compounds (Gouma et al., 2014). Research in these fields could provide much needed ground breaking discoveries.

\subsection{Bioremediation by periphyton}

De Lorenzo (2008) provides a newer approach of bioremediation with the help of algal species. Periphytons inhabit the surface waters and are an important factor in determining the primary productivity of aquatic ecosystem (Zhong et al., 2020). The components of periphyton are algae, diatoms, fungi, bacteria, protozoa as well as small multicellular animals, and organic detritus (Wu et al., 2014). These group of organisms are important aquatic 
inhabitants who determine the rate of nutrient cycling and transfer across different trophic levels of the food chains or foodwebs (Arnon et al., 2007; Azim, 2009). All these make periphyton communities an important bio-agent for remediation in aquatic ecosystems (Kanavillil \& Kurissery, 2013; Small et al., 2008). Periphyton filtration is an established remediation method for cleaning of contaminated water (Bradac et al., 2010).

\subsection{Phytoremediation - a newer approach}

Environmental pollution which affects all aspects of the biosphere is presently affecting the maintenance of global biodiversity, ecosystems, and human health. This problem cannot be rectified through existing and conventional tools and strategies. Thus this necessitates the in-depth study and understanding of the prospect of the phytoremediation potential as an important alternative technique for bioremediation. Plants have a number of inbuilt pathways and processes to counteract the stressful effects of environmental toxicants. Phtoremediation, the application of plants for bioremediation, uptakes the toxic pollutant by the plant root systems. This along with the processes of translocation, bioaccumulation, or detoxification helps restore the environmental quality. Phytoremediation is an economical, environmentally friendly, remediation technique helps to clean metal pollutants from contaminated environment (Jan et al., 2016).

Phytoremediation, uses plants to detoxify water, soil, and air pollutants, is an increasingly used bioremediation technique. In-situ and ex-situ bioremediation techniques are governed by soil and water characteristics, nutrient sustainability, soil profile, and pollutant characteristics. Most techniques are inexpensive due to the utilization of sunlight and nutrient recycling. Utilization of variety of grass and tree plantations have successfully remediated variety of wastes which are present in low concentrations and are not highly toxic.

Phytoremediation has also been successful for safely remediating organic and inorganic wastes include heavy metals, sewage sludge, and other varied wastes (McCutcheon \& Jørgensen, 2008). Phytoremediation finds application wherever the sessile water reservoir is facing short term or long term pollution. Pollutants such as heavy metals, chemical pesticides, organic solvents, petroleum products, have been remediated by phytoremediation techniques. Many plants such as plants from the Brassica family (mustard), alpine pennycress, hemp, and pigweed have proven to be successful at hyper-accumulating pollutants from contaminated surface and subsurface soil and groundwater (Speight, 2020). These plants can be harvested and the toxic wastes extracted and dealt with.

\section{Environmental pollutants - a wide spectrum}

\subsection{Degradation of xenobiotics}

Bioremediation is the application of microorganisms for restoration of polluted environment. Constant research have characterized xenobiotic degrading microorganisms. These include aromatics, halogenated aromatics, halogenated aliphatics, and pesticides. However, one main limitation of this technique is the slow rate of degradation. This is mainly due to widespread distribution of the pollutants and their very low concentrations to stimulate the degradation mechanisms. Xenobiotics present as complex mixtures require varied microbial species for efficient biodegradation (Nielsen, 2003).

\subsection{Management of industrial contaminants}

The presence of different inorganic and organic chemicals in petrochemicals, textiles, pharmaceuticals, agro-based industries, and tanneries effluents is highly hazardous to the wellbeing of the environment and human health. Physical, chemical, and advanced oxidation processes are used for industrial waste treatment. However, presence of limitations, led to the need for the development of environment friendly and economical techniques which uses lesser amount of chemicals.

Thus the biodetoxification approaches are considered as the emerging techniques. Most bioremediation techniques utilize microbial communities such as actinomycetes, bacteria, fungi, and earthworms. It is the technique of the future for degradation of harmful pollutants containing solid wastes and effluents. Many microorganisms react with pollutants to produce $\mathrm{CO}_{2}$ or $\mathrm{CH}_{4}$, water, and biomass. These toxic contaminants are enzymatically degraded to less toxic products. The solid product generated has been found to have a potential application as organic manure (Singh et al., 2020a).

\subsection{Remediation of petrochemical industry effluent}

The addition of toxic organic compounds in industrial effluents to water reservoirs has led to the worldwide necessity for development of newer, improved technologies to restore the water quality. Constituents of the effluents released from petrochemical refineries exhibit the harmful properties of carcinogenicity and mutagenicity. Phenols and their derivatives like cresols are highly due to their carcinogenic effect on human health. This necessitates that the phenols in wastewater must be detoxified before discharging into the environment (Singh et al., 2020b).

Petrochemical industry plays a major role in the growth of the Indian economy. However, with growing industrialization and urbanization, there is growing need for petrochemical production which has increased onshore and offshore exploration, refining, and oil production. Effluents from petrochemical industries contain a wide variety of organic pollutants such as complex polycyclic aromatic hydrocarbons (PAHs) which are characterized by their mutagenic, carcinogenic property and their persistence in the nature for a very long time.

These pollutants are result in ecological disturbance in aquatic biodiversity due to their toxicity. Traditional chemical methods are now being replaced by biological techniques due to their ecologically sustainable approach. 
Studies are being conducted for developing advanced bioremediation technologies for attaining better success in varied natural conditions. In bioremediation technique, though use of bacteria and bacterial consortium is well established use of fungus - mycoremediation is still in its infancy (Gupta \& Pathak, 2020). Future advancements in research will be very helpful in this field.

\subsection{Measures for remediation of marine ecosystem toxicity}

Marine oil spills have resulted in severe adverse economic and environmental impact. Major oil spills have led to worldwide awareness of marine spill effects.

Bioremediation is a technique that efficiently cleans up marine toxicity (Chen et al., 2019).

It uses marine plants or their enzymes, to rectify the condition of the contaminated environment (Atlas \& Hazen, 2011). Hydrocarbons which includes alkanes, most monoaromatics and some polycyclic aromatic hydrocarbons undergo aerobic biodegradation, whereas polar resins and asphaltenes inhibit microbial action. Bioremediation results in microorganisms metabolizing hydrocarbons from petroleum products into biomass, carbon dioxide, and water. The microbes utilize the oil as food. Light crude oils get degraded easily than diluted bitumen and heavy refined products, such as automobile oils (Abdul-Wahab, 2015). Bioremediation holds great promise for the future as an economical and efficient technique for removing oil from the contaminated site.

\subsection{Bioremediation of heavy metal pollution}

Heavy metal pollution occurs due to various anthropogenic activities and also from natural sources. Heavy metals, which displays toxicity at even very small concentrations, should be quickly removed from the environment. Heavy metals are recalcitrant, and can bioaccumulate in living tissues being mostly biomagnified at various trophic levels.

Heavy metal pollution is the direct effect of various industrial discharges (tannery, electroplating, dyeing, and mining), fertilizer, sewage sludge, and waste treatment plants (Gray, 2002). Industrial wastewater pollutes different segments of the environment such as soil and rivers. Awareness and keeping regular track of the progress of the remediation methods is the need of the hour.

Studies have shown that industrial effluents contain heavy metal concentrations above threshold limits for drinking or irrigation. If water used for irrigation in the agricultural fields is contaminated with heavy metals, it will get bioaccumulated in crops and subsequently transferred along different trophic levels in the food chains. Rivers are one of the most important fresh water reservoirs which are severely affected by duping of varied type of pollutants.

Conventional techniques like adsorption, electro-dialysis, precipitation and ion exchange are used to treat heavy metal pollution. These methods are not just complicated but also quite expensive, and require regular maintenance and monitoring. There is a growing interest in the use of biological agents for heavy metal treatment as an alternative to these older methods (Adesiyan et al., 2018). Adopting an appropriate and efficient biosorbent is currently under focus. Microorganisms impact the bioremediation processes by carrying out redox reactions. Metal-microbe interaction influences microbial growth, colonization and biofilm formation for remediation (Wuana \& Okieimen, 2011).

\section{Analysis of the benefits and limitations}

Biological remediation has advantages over traditional technologies for the management of chemical spills. One of the major benefits of bioremediation is that it is a cost and time saving pollution remediation method. The economical aspect of bioremediation is highly beneficial as compared to traditional clean-up processes.

Bioremediation is also ecologically friendly since no chemicals are added for the clean-up processes. It also does not lead to habitat loss of natural environments which sometimes occurs when using traditional methods of clean-up. During bioremediation, natural living organisms degrade the toxic contaminants into non-toxic compounds at the contaminated site, thus eliminating the necessity for transportation of the toxic compounds to another site.

Bioremediation for petroleum-related spills is a slow process. Such spills are a great threat to the existence of different ecosystems and wildlife. Based upon the severity of the requirement for clean-up, bioremediation is not always the optimum option. Pertinent to the environmental conditions at the site where the spill has taken place, providing proper nutrients for helping in the growth and maintenance of the oil degrading microorganisms may be difficult (Delille et al., 2009). All of the spilled petroleum products are cleaned up by microbes slowly, and the remaining fractions that are not degraded initially become more resistant to microbial attack (Aydin \& Icgen, 2018).

In majority of the conditions, ecosystems rarely favour for microbial degradation. Frequently, polluted sites contain a mixture of several natural and artificial contaminants. Within such combinations that are present at a site, microbes may selectively decompose the constituent that is easiest to digest. Complex microbial interaction pathways may cause some carbon compounds to be left over while others are selected for degradation. This phenomenon hampers the success and completion of the bioremediation efforts if all the contaminants are not reacted upon and detoxified at the same time.

In some cases, contaminants do not undergo complete degradation. Partial degradation might decrease the concentration of the pollutant but sometimes it creates toxic metabolic intermediates. There are some reasons why intermediate compounds accumulate. In the first case deadened products may form during cometabolism, which are products that the bacterial enzymes cannot degrade any further. In the second case the toxic intermediates build up because some of the important reaction pathways 
mediated by the bacterial system are very slow. In some cases, where the contaminants are present at very low concentrations, microorganisms may be physiologically incapable in reducing pollutant concentrations to acceptable and permissible levels, even under optimal environmental conditions, because the uptake and bacterial degradation of organic compounds may not be possible.

Finally, it is important to understand that no single set of pollutant site characteristics will favour biorectification of all chemical contaminants. Some compounds are metabolized under completely anaerobic conditions, while others are metabolized under aerobic conditions. Another reason might be that if there are two co-occurring contaminants whose degradation mechanisms are mutually exclusive, sometimes one is chosen to be degraded over the other. In such cases sequential treatment schemes need to be devised. Therefore, a case specific approach is needed for bioremediation to be successful.

Bioremediation is carried out by living organisms, primarily microorganisms, to degrade and convert the hazardous substances into their less toxic or nontoxic form. The remediation agents which are utilized can be bacteria, fungi, or plants, that decompose, detoxify, or converts the contaminants into their nontoxic form. In some instances, the microorganisms are already the members of the contaminated site or in some other cases, can be obtained from external sources and added to the site for biological treatment functions. As bioremediation primarily relies on the physiological ability of the microbes to degrade and detoxify a harmful environmental contaminant, its effectiveness is correlated with the prevalent environmental conditions that influence the microbial growth and function. Overall, the success and efficacy of the bioremediation technique depends on having physiologically active, and fast growing microorganisms to be present at the site of contamination under optimum environmental conditions (Zouboulis \& Moussas, 2011).

\section{Conclusions}

Bioremediation technology has great promise for the future which can be simultaneously used along with various conventional and traditional treatment methods for complete degradation of a wide range of environmental hazards. It is a sustainable approach for managing, controlling, and reducing environmental pollution. Extensive study and research needs to be undertaken to generate an optimum condition which facilitates the best interaction between microbes and the pollutants so that the hazardous and toxic pollutant can be successfully detoxified to restore the environmental quality as desired. Along with this, suitable techniques need to be formulated for monitoring the performance of the microbes so that this technique can be sustainable and successful.

Vermi-biofiltration and advancements in biological techniques can be widely promoted and adapted for large scale waste recycling and treatment of solid wastes which will lessen the burden of environmental pollution. Future research and development in this area will help us in better understanding of the potential threat of the pollutants on natural ecosystem, human health and setting up suitable techniques for remediating the problem. Further study in this concept will help in deciding and improving various techniques to restore and maintain the well-being of various ecosystems and all its component factors.

\section{Acknowledgements}

The authors gratefully acknowledge University of Engineering and Management, Kolkata for providing financial support and all the members of the Department of Biotechnology for their kind co-operation in completion of this study.

\section{Conflict of interest}

The authors of this paper declare that they have no conflict of interest.

\section{References}

Abdul-Wahab, M. F. (2015). Photosynthetic bacteria: An ecofriendly and cheap tool for bioremediation. Reviews in Environmental Science and Bio/Technology, 14(2), 271-285. https://doi.org/10.1007/s11157-014-9355-1

Adesiyan, I. M., Bisi-Johnson, M., Aladesanmi, O. T., Okoh, A. I., \& Ogunfowokan, A. O. (2018). Concentrations and human health risk of heavy metals in rivers in Southwest Nigeria. Journal of Health and Pollution, 8(19), 180907. https://doi.org/10.5696/2156-9614-8.19.180907

Arnon S., Packman, A. I., Peterson, C. G., \& Gray, K. A. (2007). Effects of overlying velocity on periphyton structure and denitrification. Journal of Geophysical Research, 112 (G1).

Atlas, R. M., \& Hazen, T. C. (2011). Oil biodegradation and bioremediation: A tale of the two worst spills in U.S. history. Environmental Science \& Technology, 45(16), 6709-6715. https://doi.org/10.1021/es2013227

Aydin, D. C., \& Icgen, B. (2018). Gas chromatographic analyses of kerosene bioremediation displayed distinctive pattern of $n$-alkane degradation. Petroleum Science and Technology, 36(22), 1905-1912.

https://doi.org/10.1080/10916466.2018.1517170

Azim, E. (2009). Photosynthetic periphyton and surfaces. In Encyclopedia of Inland Waters (pp. 184-191). Academic Press. https://doi.org/10.1016/B978-012370626-3.00144-7

Azubuike, C. C., Chikere, C. B., \& Okpokwasili, G. C. (2016). Bioremediation techniques-classification based on site of application: Principles, advantages, limitations and prospects. World Journal of Microbiology and Biotechnology, 32, 180. https://doi.org/10.1007/s11274-016-2137-x

Barr, D., Finnamore, J. R., Bardos, R. P., Weeks, J. M., \& Nathanail, C. P (2002). Biological methods for assessment and remediation of contaminated land: Case studies. Construction Industry Research and Information Association.

Bradac, P., Wagner, B., Kistler, D., Traber, J., Behra, R., \& Sigg, L. (2010). Cadmium speciation and accumulation in periphyton in a small stream with dynamic concentration variations. Environmental Pollution, 158(3), 641-648.

https://doi.org/10.1016/j.envpol.2009.10.031 
Brusseau, M. L. (2019). Soil and groundwater remediation. In Environmental and pollution science ( $3^{\text {rd }}$ ed., pp. 329-354). Academic Press.

https://doi.org/10.1016/B978-0-12-814719-1.00019-7

Chen, B., Ye, X., Zhang, B., Jing, L., \& Lee, K. (2019). Marine oil spills - preparedness and countermeasures. In World seas: An environmental evaluation. Volume III: Ecological issues and environmental impacts (2 ed., pp. 407-426). Academic Press. https://doi.org/10.1016/B978-0-12-805052-1.00025-5

Dana, L. D., \& Bauder, J. W. (2011). A general essay on bioremediation of contaminated soil. Montana State University.

de Lorenzo, V. (2008). Systems biology approaches to bioremediation. Current Opinion in Biotechnology, 19(6), 579-589. https://doi.org/10.1016/j.copbio.2008.10.004

Delille, D., Pelletier, E., Rodriguez-Blanco, A., \& Ghiglione, J. F. (2009). Effects of nutrient and temperature on degradation of petroleum hydrocarbons in sub-Antarctic coastal Seawater. Polar Biology, 32, 1521-1528.

https://doi.org/10.1007/s00300-009-0652-z

Frutos, F. J. G., Pérez, R., Escolano, O., Rubio, A., Gimeno, A., Fernandez, M. D., Carbonell, G., Perucha, C., \& Laguna, J. (2012). Remediation trials for hydrocarbon-contaminated sludge from a soil washing process: Evaluation of bioremediation technologies. Journal of Hazardous Materials, 199-200, 262-271. https://doi.org/10.1016/j.jhazmat.2011.11.017

Gadd, G. M. (2010). Metals, minerals and microbes: Geomicrobiology and bioremediation. Microbiology, 156(3), 609-643. https://doi.org/10.1099/mic.0.037143-0

Gouma, S., Fragoeiro, S., Bastos, A. C., \& Magan, N. (2014). Bacterial and fungal bioremediation strategies. In Microbial Degradation and Bioremediation (pp. 301-323). Elsevier. https://doi.org/10.1016/B978-0-12-800021-2.00013-3

Gray, J. S. (2002). Biomagnification in marine systems: The perspective of an ecologist. Marine Pollution Bulletin, 45(1-12), 46-52. https://doi.org/10.1016/S0025-326X(01)00323-X

Gupta, S., \& Pathak, B. (2020). Mycoremediation of polycyclic aromatic hydrocarbons. In Abatement of environmental pollutants: Trends and strategies (pp. 127-149). Elsevier. https://doi.org/10.1016/B978-0-12-818095-2.00006-0

Hazen, T. C. (2010). Cometabolic bioremediation. In Handbook of hydrocarbon and lipid microbiology (pp. 2505-2514). Springer. https://doi.org/10.1007/978-3-540-77587-4_185

Herrero, M., \& Stuckey, D. (2015). Bioaugmentation and its application in wastewater treatment: A review. Chemosphere, 140, 119-128. https://doi.org/10.1016/j.chemosphere.2014.10.033

Jan, S., Rashid, B., Azooz, M. M., Hossain, M. A., \& Ahmad, P. (2016). Genetic strategies for advancing phytoremediation potential in plants: A recent update. In Plant metal interaction: Emerging remediation techniques (pp. 431-454). Elsevier. https://doi.org/10.1016/B978-0-12-803158-2.00017-5

Kanavillil, N., \& Kurissery, S. (2013). Temporal variation of periphyton communities: A 3-year study from northwest Lake Simcoe, Ontario, Canada. Inland Waters, 3(4), 473-486. https://doi.org/10.5268/IW-3.4.525

Karigar, C. S., \& Rao, S. S. (2011). Role of microbial enzymes in the bioremediation of pollutants: A review. Enzyme Research, 2011(1), 1-11. https://doi.org/10.4061/2011/805187

Leung, M. (2004). Bioremediation: Techniques for cleaning up a mess. Journal of Biotechnology, 2, 18-22.

Mackay, D., \& Fraser, A. (2000). Bioaccumulation of persistent organic chemicals: Mechanisms and models. Environmental Pollution, 110(3), 375-391.

https://doi.org/10.1016/S0269-7491(00)00162-7
McCutcheon, S. C., \& Jørgensen, S. E. (2008). Phytoremediation. In Encyclopedia of ecology (pp. 2751-2766). Academic Press. https://doi.org/10.1016/B978-008045405-4.00069-0

Nielsen, J. (2003). Metabolic engineering. In Encyclopaedia of physical science and technology ( $3^{\text {rd }}$ ed., pp. 391-406). Academic Press. https://doi.org/10.1016/B0-12-227410-5/00422-1

Pointing, S. B. (2001). Feasibility of bioremediation by whiterot fungi. Applied Microbiology and Biotechnology, 57(1-2), 20-33. https://doi.org/10.1007/s002530100745

Pushpanathan, M., Jayashree, S., Gunasekharan, P., \& Rajendhran, J. (2014). Microbial bioremediation: A metagenomic approach. In Microbial Biodegradation and Bioremediation (pp. 407-419). Elsevier. https://doi.org/10.1016/B978-0-12-800021-2.00017-0

Rai, P. K., \& Chutia, B. M. (2016). Particulate Matter bio-monitoring through magnetic properties of an Indo-Burma hotspot region. Chemistry and Ecology, 32(6), 1-13. https://doi.org/10.1080/02757540.2016.1157173

Singh, P., Singh, V. K., Singh, R., Borthakur, A., Madhav, S., Ahamad, A., Kumar, A., Pal, D. B., Tiwary, D., \& Mishra, P. K. (2020a). Bioremediation: A sustainable approach for management of environmental contaminants. In Abatement of environmental pollutants: Trends and strategies (pp. 1-23). Elsevier. https://doi.org/10.1016/B978-0-12-818095-2.00001-1

Singh, T., Bhatiya, A. K., Mishra, P. K., \& Srivastava, N. (2020b). An effective approach for the degradation of phenolic waste: phenols and cresols. In Abatement of environmental pollutants: Trends and strategies (pp. 203-243).

https://doi.org/10.1016/B978-0-12-818095-2.00011-4

Skipper, H. D., \& Turco, R. F. (Eds.). (1995). Bioremediation: Science and applications: Vol. 43. SSSA special publication. Soil Science Society of America. John Wiley \& Sons, Inc.

Small, A., Bunn, A., McKinstry, C., Peacock, A., \& Miracle, A. L. (2008). Investigating freshwater periphyton community response to uranium with phospholipid fatty acid and denaturing gradient gel electrophoresis analyses. Journal of Environmental Radioactivity, 99(4), 730-738.

https://doi.org/10.1016/j.jenvrad.2007.09.009

Speight, J. G. (2020). Natural water remediation: Chemistry and technology. Elsevier.

https://doi.org/10.1016/B978-0-12-803810-9.00001-2

Vidali, M. (2001). Bioremediation. An overview. Pure and Applied Chemistry, 73(7), 1163-1172. https://doi.org/10.1351/pac200173071163

Wu, Y., Xia, L., Yu, Z., Shabbir, S., \& Kerr, P. G. (2014). In situ bioremediation of surface waters by periphytons. Bioresource Technlogy, 151, 367-372. https://doi.org/10.1016/j.biortech.2013.10.088

Wuana, R. A., \& Okieimen, F. E. (2011). Heavy metals in contaminated soils: A review of sources, chemistry, risks and best available strategies for remediation. International Scholarly Research Notices, 2011, 402647. https://doi.org/10.5402/2011/402647

Zhong, W., Zhao, W., \& Song, J. (2020). Responses of periphyton microbial growth, activity, and pollutant removal efficiency to $\mathrm{Cu}$ exposure. International Journal of Environmental Research and Public Health 17(3), 941.

https://doi.org/10.3390/ijerph17030941

Zouboulis, A. I., \& Moussas, P. A. (2011). Groundwater and soil pollution: Bioremediation. In Encyclopaedia of Environmental Health (pp. 1037-1044). Elsevier.

https://doi.org/10.1016/B978-0-444-52272-6.00035-0 